\title{
Introdução à teoria do reconhecimento de Axel Honneth*
}

\author{
Giovani Agostini Saavedra e Emil Albert Sobottka**
}

Axel Honneth é o atual representante da tradição da teoria crítica da Escola de Frankfurt. Sua teoria foi desenvolvida em dois momentos distintos. Em um primeiro momento, ele procura mostrar as insuficiências da versão da teoria crítica desenvolvida por Jürgen Habermas. Honneth sustenta que a teoria habermasiana da sociedade precisa ser criticada do ponto de vista do horizonte da dimensão de intersubjetividade social, na qual as instituições estão inseridas. Em um segundo momento, Honneth procura desenvolver sua própria versão da teoria crítica ex negativo: ele esclarece no posfácio de Kritik der Macht que a primeira versão da teoria habermasiana da sociedade poderia ser melhor desenvolvida a partir do conceito hegeliano de luta por reconhecimento. ${ }^{1}$ Nesse sentido, poder-se-ia concluir que Honneth, em Kritik der

* Com o presente artigo, pretende-se apresentar ao leitor uma breve introdução nos conceitos fundamentais da obra de Axel Honneth. Isso significa, dentre outras coisas, que não se procurará desenvolver aqui nenhuma tese específica a respeito da teoria do representante da terceira geração da escola de Frankfurt. Procurar-se-á, ao contrário, reconstruir de forma mais neutra e clara possível os argumentos centrais da teoria crítica de Axel Honneth, de forma a facilitar a leitura de sua obra e situar o seu pensamento na tradição da escola de Frankfurt.

** Giovani A. Saavedra é doutor em Direito e Filosofia pela Universidade de Frankfurt, professor do PPG em Ciências Criminais da Pucrs; publicou, entre outros, Jurisdição e democracia (Livraria do Advogado, 2006); Emil A. Sobottka é doutor em Sociologia e Ciência Política pela Universidade de Münster, professor na Pucrs e pesquisador do CNPq.

1 Ver, a esse respeito, o Posfácio (1988) em: Axel Honneth, Kritik der Macht, p. 386 e o Prefácio do livro Luta por Reconhecimento. A gramática moral dos conflitos sociais, São Paulo: Ed. 34, 2003.

ก. 1

p. $9-18$ jan.-abr. 2008 
Macht, procura mostrar, principalmente, que uma teoria crítica da sociedade deveria estar preocupada em interpretar a sociedade a partir de uma única categoria, isto é, do reconhecimento.

Em Kampf um Anerkennung, Honneth desenvolve essa conclusão de forma conseqüente. Ali ele introduz os primeiros elementos da sua teoria do reconhecimento a partir da categoria da dependência absoluta, de Winnicott. Esta categoria designa a primeira fase do desenvolvimento infantil, na qual a mãe e o bebê se encontram num estado de relação simbiótica. A carência e a dependência total do bebê e o direcionamento completo da atenção da mãe para a satisfação das necessidades da criança fazem com que entre eles não haja nenhum tipo de limite de individualidade e ambos se sintam como unidade (Honneth, 2003, p. 160s). Aos poucos, com o retorno gradativo aos afazeres da vida diária, este estado de simbiose vai se dissolvendo por meio de um processo de ampliação da independência de ambos, pois, com a volta à normalidade da vida, a mãe não está mais em condições de satisfazer as necessidades da criança imediatamente.

A criança, então em média com 6 meses de vida, precisa se acostumar com a ausência da mãe. Essa situação estimula na criança o desenvolvimento de capacidades que a tornam capaz de se diferenciar do seu ambiente. Winnicott atribui a essa nova fase o nome de relativa independência. Nesta fase, a criança reconhece a mãe não mais como uma parte do seu mundo subjetivo e sim como um objeto com direitos próprios. A criança trabalha esta nova experiência por meio de dois mecanismos, que Honneth chama de destruição e fenômeno de transição. O primeiro mecanismo é interpretado, por Honneth, a partir dos estudos de Jessica Benjamin. Jessica Benjamin constata que os fenômenos de expressão agressiva da criança nesta fase acontecem na forma de uma espécie de luta, que ajuda a criança a reconhecer a mãe como um ser independente com reivindicações próprias. A mãe precisa, por outro lado, aprender a aceitar o processo de amadurecimento que o bebê está passando. A partir dessa experiência de reconhecimento recíproco, os dois começam a vivenciar também uma experiência de amor recíproco sem regredir a um estado simbiótico (Honneth, 2003, p. 164). A criança, porém, só estará em condições de desenvolver o segundo mecanismo se ela tiver desenvolvido com o primeiro mecanismo uma experiência elementar de confiança na dedicação da mãe.

Então, com base nos estudos de Winnicott, Honneth esboça os princípios fundamentais do primeiro nível de reconhecimento. Quando a criança experimenta a confiança no cuidado paciencioso e duradouro da mãe, ela passa a 
estar em condições de desenvolver uma relação positiva consigo mesma. Honneth chama essa nova capacidade da criança de autoconfiança (Selbstvertrauen). De posse dessa capacidade, a criança está em condições de desenvolver de forma sadia a sua personalidade. Esse desenvolvimento primário da capacidade de autoconfiança é visto por Honneth (2003, p. 168ss) como a base das relações sociais entre adultos. Honneth vai além e sustenta que o nível do reconhecimento do amor é o núcleo fundamental de toda a moralidade (ibid., p. 172ss). Portanto, este tipo de reconhecimento é responsável não só pelo desenvolvimento do auto-respeito (Selbstachtung), mas também pela base de autonomia necessária para a participação na vida pública (ibid., p. 174).

Duas perguntas guiam a análise honnethiana da segunda esfera do reconhecimento: (1) Qual é o tipo de auto-relação que caracteriza a forma de reconhecimento do direito? (2) Como é possível que uma pessoa desenvolva a consciência de ser sujeito de direito? A estratégia utilizada por Honneth consiste em apresentar o surgimento do direito moderno de tal forma que, neste fenômeno histórico, também seja possível encontrar uma nova forma de reconhecimento. Honneth pretende, portanto, demonstrar que o tipo de reconhecimento característico das sociedades tradicionais é aquele ancorado na concepção de status: em sociedades desse tipo, um sujeito só consegue obter reconhecimento jurídico quando ele é reconhecido como membro ativo da comunidade e apenas em função da posição que ele ocupa nesta sociedade. Honneth reconhece na transição para a modernidade uma espécie de mudança estrutural na base da sociedade, à qual corresponde também uma mudança estrutural nas relações de reconhecimento: ao sistema jurídico não é mais permitido atribuir exceções e privilégios às pessoas da sociedade em função do seu status. Pelo contrário, o sistema jurídico deve combater estes privilégios e exceções. $O$ direito então deve ser geral o suficiente para levar em consideração todos interesses de todos os participantes da comunidade. A partir desta constatação, a análise do direito que Honneth procura desenvolver consiste basicamente em explicitar o novo caráter, a nova forma do reconhecimento jurídico que surgiu na modernidade (Honneth, 2003, p. 178ss).

Honneth procura mostrar que, junto com o surgimento de uma moral ou de uma sociedade pós-tradicional, houve também uma separação da função do direito e daquela do juízo de valor (Wertschätzung). Na teoria de Ihrering e na tradição kantiana de diferenciação de duas formas de Respeito (Achtung), principalmente com base na pesquisa de Darwall, ele encontra elementos para determinar a diferença entre direito e juízo de valor. Para o direito, a pergunta 
central é: como a propriedade constitutiva das pessoas de direito deve ser definida; no caso do juízo de valor: como se pode desenvolver um sistema de valor que está em condições de medir o valor das propriedades características de cada pessoa (ibid., p. 183ss).

Os sujeitos de direito precisam estar em condições de desenvolver sua autonomia, a fim de que possam decidir racionalmente sobre questões morais. Aqui Honneth tem em mente a tradição dos direitos fundamentais liberais e do direito subjetivo em condições pós-tradicionais, que indicam a direção do desenvolvimento histórico do direito (ibid., p. 190ss). A luta por reconhecimento deveria então ser vista como uma pressão, sob a qual permanentemente novas condições para a participação na formação pública da vontade vêm à tona. Honneth esforça-se, naturalmente influenciado pelos escritos de T. H. Marshall (1967), para mostrar que a história do direito moderno deve ser reconstruída como um processo direcionado à ampliação dos direitos fundamentais. Apesar de Honneth sempre utilizar um conceito problemático de direito subjetivo, a sua correta intuição pode ser compreendida claramente quando ele explicita a sua interpretação da reconstrução histórica de Marshall: os atores sociais só conseguem desenvolver a consciência de que eles são pessoas de direito, e agir conseqüentemente, no momento em que surge historicamente uma forma de proteção jurídica contra a invasão da esfera da liberdade, que proteja a chance de participação na formação pública da vontade e que garanta um mínimo de bens materiais para a sobrevivência (Honneth, 2003, p. 190). Honneth sustenta que as três esferas dos direitos fundamentais, diferenciadas historicamente, são o fundamento da forma de reconhecimento do direito. Por conseguinte, reconhecer-se reciprocamente como pessoas jurídicas significa hoje muito mais do que no início do desenvolvimento do direito: a forma de reconhecimento do direito contempla não só as capacidades abstratas de orientação moral, mas também as capacidades concretas necessárias para uma existência digna (ibid.), em outras palavras, a esfera do reconhecimento jurídico cria as condições que permitem ao sujeito desenvolver auto-respeito (selbstachtung) (ibid., p. 194ss).

No caso da forma de reconhecimento do direito, são postas em relevo as propriedades gerais do ser humano. No caso da valoração social, são postas em relevo as propriedades que tornam o indivíduo diferente dos demais, ou seja, as propriedades de sua singularidade. Portanto, Honneth parte do princípio de que a terceira forma de reconhecimento, a saber, a comunidade de valores ou solidariedade, deve ser considerada um tipo normativo ao qual correspondem as diversas formas práticas de auto-relação valorativa 
(Selbstschätzung). Honneth não aceita aquilo que Hegel e Mead consideram condição deste padrão de reconhecimento, pois ambos os autores estão convencidos da existência de um horizonte valorativo e intersubjetivo compartilhado por todos os membros da sociedade como condição da existência da forma de relacionamento que Honneth chama de solidariedade. Honneth procura mostrar, ao contrário, que com a transição da sociedade tradicional para a sociedade moderna surge um tipo de individualização que não pode ser negado. A terceira esfera do reconhecimento deveria ser vista, então, como um meio social a partir do qual as propriedades diferenciais dos seres humanos venham à tona de forma genérica, vinculativa e intersubjetiva (ibid., p. 197). Honneth identifica um segundo nível desta terceira esfera do reconhecimento (solidariedade). No nível de integração social encontram-se valores e objetivos que funcionam como um sistema de referência para a avaliação moral das propriedades pessoais dos seres humanos e cuja totalidade constitui a autocompreensão cultural de uma sociedade. A avaliação social de valores estaria permanentemente determinada pelo sistema moral dado por esta autocompreensão social. Esta esfera de reconhecimento está vinculada de tal forma em uma vida em comunidade que a capacidade e o desempenho dos integrantes da comunidade somente poderiam ser avaliadas intersubjetivamente (ibid.).

Como no caso das relações jurídicas, Honneth analisa a transição da sociedade de tipo tradicional para a moderna como uma espécie de mudança estrutural desta terceira esfera de reconhecimento: assim que a tradição hierárquica de valoração social, progressivamente, vai sendo dissolvida, as formas individuais de desempenho começam a ser reconhecidas. Honneth parte do princípio que uma pessoa desenvolve a capacidade de sentir-se valorizada somente quando as suas capacidades individuais não são mais avaliadas de forma coletivista. Daí resulta que uma abertura do horizonte valorativo de uma sociedade às variadas formas de auto-realização pessoal somente se dá com a transição para a modernidade. Em função dessa mudança estrutural existe, porém, no centro da vida moderna uma permanente tensão, um permanente processo de luta, porque nesta nova forma de organização social há, de um lado, uma busca individual por diversas formas de auto-realização e, de outro, a busca de um sistema de avaliação social (ibid., p. 204ss). Essa espécie de tensão social que oscila permanentemente entre a ampliação de um pluralismo valorativo que permita o desenvolvimento da concepção individual de vida boa e a definição de um pano de fundo moral que sirva de ponto de referência para avaliação social da moralidade faz da sociedade moderna uma espécie de arena na qual se desenvolve ininterruptamente uma luta por reconhecimento: os diversos grupos sociais precisam desenvolver a capacida- 
de de influenciar a vida pública a fim de que sua concepção de vida boa encontre reconhecimento social e passe, então, a fazer parte do sistema de referência moral que constitui a autocompreensão cultural e moral da comunidade em que estão inseridos. Além disso, com o processo de individualização das formas de reconhecimento surge nesta esfera de reconhecimento a possibilidade de um tipo específico de auto-relação: a autoestima (Selbstschätzung). A Solidariedade na sociedade moderna está vinculada à condição de relações sociais simétricas de estima entre indivíduos autônomos e à possibilidade de os indivíduos desenvolverem a sua auto-realização (Selbstverwirklichung) (ibid., p. 209ss). Simetria significa aqui que os atores sociais adquirem a possibilidade de vivenciarem o reconhecimento de suas capacidades numa sociedade não-coletivista.

Para que os atores sociais possam desenvolver um auto-relacionamento (Selbstbeziehung) positivo e saudável, eles precisam ter a chance simétrica de desenvolver a sua concepção de vida boa sem sofrerem os sintomas das patologias oriundas das experiências de desrespeito (Mißachtung). Porque à experiência do reconhecimento corresponde sempre uma forma positiva de autorelacionamento (Selbsterfahrung), Honneth precisa partir do princípio de que o conteúdo do que seja desrespeito deve estar implicitamente vinculado nas reivindicações individuais por reconhecimento: se e quando o sujeito social faz uma experiência de reconhecimento, ele adquire um entendimento positivo sobre si mesmo; se e quando, ao contrário, um ator social experimenta uma situação de desrespeito, conseqüentemente, a sua auto-relação positiva, adquirida intersubjetivamente, adoece.

Para tornar a sua teoria plausível, Honneth precisa, por consequêencia, encontrar na história social traços de uma tipologia tripartite negativa da estrutura das relações de reconhecimento. Esta tipologia negativa deve cumprir duas tarefas: (1) para cada esfera de relação de reconhecimento deve surgir um equivalente negativo, com o qual a experiência de desrespeito possa ser esclarecida, seguindo a estrutura da forma de reconhecimento correspondente; (2) a experiência de desrespeito deve ser ancorada de tal forma em aspectos afetivos do ser humano, que a sua capacidade motivacional de desencadeamento de uma luta por reconhecimento venha à tona.

À primeira esfera de reconhecimento, o amor, correspondem as formas de desrespeito definidas por Honneth como maus tratos (Mißhandlung) e violação (Vergewaltigung). Nesta forma de desrespeito o componente da personalidade atacado é aquele da integridade psíquica, ou seja, não é diretamente a integridade física que é violentada, mas sim o auto-respeito 
(selbstvertändliche Respektierung) que cada pessoa possui de seu corpo e que, segundo Winnicott, é adquirido por meio do processo intersubjetivo de socialização originado através da dedicação afetiva (Honneth, 2003, p. 214ss).

À forma de reconhecimento do direito corresponde a forma de desrespeito intitulada privação de direitos (Entrechtung). Nesta esfera do reconhecimento o componente da personalidade que é ameaçado é aquela da integridade social. Também aqui o desrespeito se refere a um tipo específico de autorelação, a saber, o auto-respeito. Central para a análise das formas de desrespeito feita por Honneth é o fato de que todo o tipo de privação violenta da autonomia deve ser vista como vinculada a uma espécie de sentimento. $\mathrm{O}$ sentimento de injustiça ocupa um papel importante na análise que Honneth faz do direito (ibid., p. 219). Porém, apesar de Honneth ressaltar em um primeiro momento o papel do sentimento de injustiça, logo em seguida a sua análise passa a considerar um tipo de respeito cognitivo da capacidade de responsabilidade moral, que um ator social vivencia numa situação de desrespeito jurídico. Portanto, o que significa ser uma capacidade para responsabilidade moral de uma pessoa deve ser medido no grau de universalização e também no grau de materialização do direito (ibid., p. 219).

À forma de reconhecimento da solidariedade corresponde a forma de desrespeito da degradação moral (Entwürdigung) e da injúria (Beleidigung). Honneth entende que a dimensão da personalidade ameaçada é aquela da dignidade (Würde). A experiência de desrespeito deve ser encontrada na degradação da autoestima (Selbstschätzung), ou seja, a pessoa aqui é privada da possibilidade de desenvolver uma estima positiva de si mesma (ibid., p. 217).

Para esclarecer as formas de desrespeito Honneth adota o conceito psicanalítico de patologia. Todas essas formas de desrespeito são, portanto, uma forma de patologia. Assim, uma teoria do reconhecimento deveria ser capaz de indicar a classe de sintomas que os atores sociais atingidos pela forma de desrespeito em seu estado patológico deixam transparecer (ibid., p. 219). Os sinais corporais do sofrimento psíquico devem ser vistos, portanto, como expressões exteriores, ou melhor, como reações externas de sentimentos patológicos interiores ou psíquicos. Dessa forma, somente as experiências de injustiça que acarretam fenômenos patológicos devem ser consideradas fenômenos de desrespeito (ibid., p. 219ss).

As reações provocadas pelo sentimento de injustiça devem ser vistas como o estopim par excellence da luta por reconhecimento. Com ajuda dos estudos desenvolvidos por Dewey, Honneth procura mostrar que uma experiência social de desrespeito atua como uma forma de freio social que pode levar à 
paralisia do indivíduo ou de um grupo social. Por outro lado, ela mostra o quanto o ator social é dependente do reconhecimento social. Honneth sustenta que o indivíduo está sempre vinculado em uma complexa rede de relações intersubjetivas e que, conseqüentemente, ele é dependente estruturalmente do reconhecimento dos outros indivíduos (ibid., p. 224). A experiência do desrespeito, então, deve ser tal que forneça a base motivacional da luta por reconhecimento, porque essa tensão afetiva só pode ser superada quando o ator social estiver em condições de voltar a ter uma participação ativa e sadia na sociedade (ibid., p. 224). É exatamente porque os seres humanos nunca reagem de forma neutra a esse tipo de enfermidade social, que o sentimento de injustiça acaba sendo o estopim da luta por reconhecimento.

Como todo o sentimento, o sentimento de injustiça diz pouca coisa sobre o conteúdo normativo das relações de reconhecimento. Em outras palavras, os sentimentos de injustiça podem indicar um problema, mas não a sua solução. Honneth entende que é necessária a articulação política de um movimento social para que o sentimento de injustiça do indivíduo passe a ter relevância política (ibid., p. 224ss).

Aqui, porém, não fica muito claro qual deve ser a ponte explicativa entre os objetivos impessoais dos movimentos sociais e um sentimento privado de injustiça. Honneth sustenta que, ao contrário dos modelos atomísticos, utilitaristas ou intencionistas de explicação dos movimentos sociais, o surgimento de um movimento social deve ser explicado a partir da existência de uma semântica coletiva que permita a interpretação das experiências individuais de injustiça, de forma que não se trate mais aqui de uma experiência isolada de um indivíduo, mas sim de um círculo intersubjetivo de sujeitos que sofrem da mesma patologia social (cf. ibid. p. 262ss). Aqui Honneth está fazendo jus à crítica hegeliana do atomismo à medida que ele retira do indivíduo a capacidade de explicar os problemas sociais. O indivíduo só pode ser considerado como tal se é considerada a existência anterior de uma sociedade que lhe dá sentido.

Portanto, quanto mais forte for a influência da luta por reconhecimento de um determinado grupo, ou quanto maior for o número de exigências sociais em função de uma mudança específica, mais haverá de surgir, por conseqüência, uma espécie de horizonte de interpretação subcultural que explicará a relação motivacional entre sentimento individual de injustiça e luta coletiva por reconhecimento. Na inserção em um grupo social que busca um determinado tipo de reconhecimento, os atores sociais experimentam, concomitantemente, um tipo de reconhecimento antecipado de uma socieda- 
de futura em que a sua reivindicação social será reconhecida socialmente e, dessa forma, o indivíduo tem de volta um pouco do reconhecimento perdido.

Por fim, através de uma análise crítica dos estudos históricos de E. P. Thompson e Barrington Moore, Honneth procura mostrar que por trás dos acontecimentos histórico há um processo de desenvolvimento moral que somente se deixa explicar a partir da lógica da ampliação das relações de reconhecimento. $\mathrm{O}$ modelo da luta por reconhecimento deve, portanto, cumprir duas tarefas: (1) ser um modelo de interpretação do surgimento das lutas sociais e (2) do processo de desenvolvimento moral. Só então esse modelo estará em condições de realizar uma ordenação sistemática dos fenômenos históricos e sociais, que sem esse modelo permaneceriam amorfos.

Dessa forma, os sentimentos morais assumem a função de aceleração ou retardamento da evolução moral e histórica da sociedade e o modelo da luta por reconhecimento passa a ser visto como o ponto de vista normativo, a partir do qual é possível definir o estágio atual do desenvolvimento moral da sociedade (Honneth, 2003, p. 270ss). O ponto de partida de um tal processo de formação moral precisa ser, portanto, um momento histórico, em que o modelo tripartite do reconhecimento ainda não se diferenciou. Honneth caracteriza tal processo como um processo de aprendizagem que tem a capacidade de esclarecer ao mesmo tempo a diferenciação as esferas do reconhecimento e o potencial que elas carregam internamente para o desenvolvimento moral da sociedade. O modelo da luta por reconhecimento explicita, então, uma gramática, uma semântica subcultural, na qual as experiências de injustiça encontram uma linguagem comum, que indiretamente oferece a possibilidade de uma ampliação das formas de reconhecimento (ibid., p. 272). Com isso, Honneth pretende mostrar que a análise dos acontecimentos sociais é uma tarefa da área da interpretação, que permite explicar esses acontecimentos como estágios de um processo de formação moral que se dá por meio do conflito e cuja direção é dada pela idéia-guia da ampliação das relações de reconhecimento (ibid., p. 273).

Essas são as idéias básicas que marcaram o início da teoria do reconhecimento de Axel Honneth e que permanecem intactas até hoje. Porém, o autor tem se deparado desde a publicação do livro Luta por Reconhecimento com três problemas específicos: (1) Como é possível combinar a idéia hegeliana de luta por reconhecimento com as instituições de um estado democrático de direito? (2) Como é possível pensar instituições a partir do conceito de reconhecimento, dado que Axel Honneth, desde o início, e ainda hoje, pretende desenvolver esse conceito sem se fazer valer, como Habermas, da teoria dos 
sistemas? (3) E, por último: será que as relações de reconhecimento são constitutivas da forma de "ser-humano" dos seres humanos? Ou, com outras palavras: será que as relações de reconhecimento têm uma dimensão antropológica? Esses três problemas são enfrentados pelo autor nos dois textos inéditos que estão sendo publicados nesta revista e o presente artigo tinha o condão de introduzir o leitor nesta problemática. Afinal, nada melhor do que deixar o próprio autor explicitar a forma como ele pretende desenvolver a própria teoria.

\section{Referências}

HONNETH, Axel. Kampf um Anerkennung: Zur moralischen Grammatik sozialer Konflikte. Frankfurt am Main: Suhrkamp, 2003.

Kritik der Macht: Reflexionsstufen einer kritischen Gesellschaftstheorie.

Frankfurt am Main: Suhrkamp, 2000.

MARSHALL, T. H. Cidadania, classe social e status. Rio de Janeiro: Zahar Editores, 1967. 